\title{
e-Interview
}

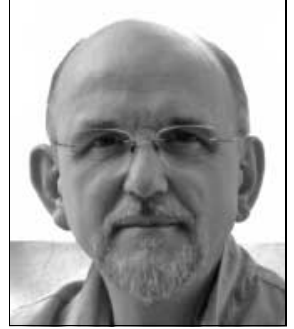

\section{Jed Boardman, PhD FRCPsych}

Jed Boardman is a consultant psychiatrist and senior lecturer in social psychiatry with South London and Maudsley NHS Foundation Trust and a senior policy advisor for the Centre for Mental Health. He trained at Guy's Hospital Medical School. His special interests include social and community psychiatry and development of recoveryoriented practices and services.

If you were not a psychiatrist, what would you do?

Probably something in the legal field. But a more fanciful area of work would be to be a skilled craftsman.

What has been the greatest impact of your profession on you personally? What perhaps medicine and psychiatry allow a person to do is to develop professional skills and expertise at the same time as retaining a human perspective. But it is important to appreciate the nature of the power that a professional training gives us and to use this to achieve decent ends.

\section{Do you feel stigmatised by your profession?}

This is probably something that is difficult to escape and it reflects the prejudice experienced by those who use mental health services. These are general social attitudes and actions that still pervade the thinking of health professionals.

\section{What are your interests outside of work?}

I have collected modern first editions for many years, but this is now prohibitively expensive. I have always enjoyed sports and have recently taken up bowls.

\section{Who was your most influential trainer, and why?}

Jim Watson (J. P. W.) encouraged me to take up psychiatry in the first place. My early experience of community psychiatry with Douglas Brough was influential in my later thinking on the organisation of mental health services and my approach to them.
What job gave you the most useful training experience?

During my training I worked as a research registrar at the Handen Road Community Mental Health Centre in Lewisham and subsequently at the National Unit for Psychiatric Research and Development (which later became the Sainsbury Centre for Mental Health). This sealed not only my interest in community psychiatry, but also my approach to combining clinical work with research and a social perspective.

Which publication has influenced you most? Not one, but several - psychiatric-related publications were Brown and Harris's Social Origins of Depression, Richard Warner's Recovery from Schizophrenia, and Goldberg and Huxley's Pathways to Psychiatric Care. Perhaps I should add Emile Zola's Germinal as a piece of influential literature and George Orwell's

Down and Out in Paris and London as a work of literary journalism. All have something to say about the historical and social context we live and work in.

How has the political environment influenced your work?

I have always taken the view (influenced from medical school days) that medicine and health are fundamentally political, and have taken a keen interest in economics and politics, especially their influences on social policy. The post-war development of the National Health Service and Welfare State have been, I think, the predominant influences on the way in which we practice psychiatry and on the delivery of mental health services in the UK.

\section{What part of your work gives you the} most satisfaction?

Currently, the development of recoveryoriented services, which combines possibility of improving practice and the quality of services with that of improving social justice for people with mental health problems.

\section{What do you least enjoy?}

Bureaucracy.

What is the most promising opportunity facing the profession?

The possibility of creating a different approach to our relationship with patients that views this as a partnership between experts.

\section{What is the greatest threat?}

Current proposals for reform of the NHS. The chief threats here come from the private sector, the possibility of putting profits before patients and the creation of even larger health inequalities than we have now.
What single change would substantially improve quality of care?

Reduction of institutional and bureaucratic thinking that get in the way of developing imaginative ways of working and are a barrier to kind and flexible approaches towards people who use mental health services and staff who work in them.

\section{What conflict of interest do you} encounter most often?

In our profession, this most commonly relates to our relationship with the pharmaceutical industry. In daily practice, perhaps the most common is the conflict between what I might think is good for someone, and what they want or think is best.

What is the most important advice you could offer to a new trainee?

Make sure to develop a good balance of the scientific and human approaches in your clinical practice. And find an area of special interest or expertise that you really enjoy and which compliments your best skills.

What are the main ethical problems that psychiatrists will face in the future?

The influence of pharmaceutical companies in the domination of treatments and that of the state in controlling individuals.

What is the role of the psychiatrist in rebuilding healthcare systems?

This has always been important and we can offer our experience of working on the ground level, our clinical and historical perspectives and our research knowledge, particularly that derived from epidemiology. This, in partnership with others, can be a very powerful influence.

What single change to mental health legislation would you like to see? Abandon CTOs. But the current legislative problem is that of welfare reform, which I believe is misguided and unjust, reinforcing the old dichotomy of the 'deserving' and 'undeserving' poor and disadvantaging people with disabilities of all kinds. We need to develop a welfare system that does not stigmatise poverty and that empowers people with disabilities but also protects them when they are at their most vulnerable.

What single area of psychiatric practice is most in need of development?

Practice that increases hope, agency and opportunity.

What single area of psychiatric research should be given priority?

Programmes designed to improve and evaluate mental health services.

How would you like to be remembered? For doing a good job.

Dominic Fannon

doi: 10.1192/pb.bp.111.036582 